\title{
EDUCAÇÃO PERMANENTE E A CONSTRUÇÃO DE TRAJETÓRIAS PROFISSIONAIS
}

\section{ARTIGO ORIGINAL}

OLIVEIRA, Rejane Aparecida de ${ }^{1}$

SILVA, Walto Luiz da ${ }^{2}$

OLIVEIRA, Rejane Aparecida de. SILVA, Walto Luiz da. Educação Permanente e a construção de trajetórias profissionais. Revista Científica Multidisciplinar Núcleo do Conhecimento. Ano 05, Ed. 10, Vol. 14, pp. 81-95. Outubro de 2020. ISSN: 24480959, Link de acesso: https://www.nucleodoconhecimento.com.br/educacao/educacao-permanente

\section{RESUMO}

Na perspectiva de uma educação permanente, onde os indivíduos devem se educar ao longo da vida, está implícita a necessidade de buscar alternativas visando enfrentar desafios do mundo do trabalho originários da atual sociedade do conhecimento e da informação. Entretanto, essa concepção de educação está direcionada predominantemente para a competição difundida na órbita das relações sociais capitalistas. Com o avanço tecnológico as relações sociais e toda a estrutura social no processo de produção trouxeram grandes desafios para a atual sociedade, e a escola como disseminadora da educação também se adequou a nova realidade, tendo um ensino amplo e contínuo na formação do cidadão, com uma educação permanente a qual contribui para o aperfeiçoamento constante da formação profissional, num

${ }^{1}$ Pós Graduada em Psicopedagogia, Licenciatura em Administração de Empresas, MBA em Finanças, Bacharel em Administração de Empresas.

2 Técnico em Contabilidade, Bacharel em Administração de Empresas, Formação Pedagógica de Docentes em Administração de Empresas, MBA em Gestão Estratégicas em Recursos Humanos, Licenciado em Pedagogia. 
contexto histórico marcado pela velocidade das mudanças que ocorreram no mundo da produção em função do avanço tecnológico devido a globalização. Diante disso, torna-se importante compreender as diferentes visões sobre esse conceito e sua importância para o processo educacional brasileiro.

Palavras-Chave: Educação permanente, trabalho, globalização.

\section{INTRODUÇÃO}

Alguns aspectos das relações entre educação e trabalho suscitam intensos debates na sociedade atual que refleti sobre o papel da educação num contexto histórico no qual é possível diagnosticar grande parcela da população ativa excluída do mundo do trabalho ou sujeita a condições degradantes, principalmente em razão das consequências da evolução das novas tecnologias devido a globalização, assim como previa McLuhan (1969), no processo produtivo e da reestruturação organizacional adotada por grande parte das empresas.

Os problemas engendrados por essa nova realidade social devem ser discutidos exaustivamente pelos diferentes atores sociais, principalmente pelos profissionais envolvidos com o processo educacional, porque, pela natureza de suas próprias competências, possuem papel importante na formação dos cidadãos brasileiros.

Pensando a educação como um processo em que a sociedade busca formar seus membros para melhor nela viver (ORSO, 2012), esse ensinar - pelo uso de novas tecnologias, onde os educadores devem conhecer as transformações que ocorrem no mundo da produção e do trabalho para que possam pensar uma ação pedagógica permanente. 


\section{EDUCAÇÃO PERMANENTE E A CONSTRUÇÃO DE TRAJETÓRIAS PROFISSIONAIS}

Educação permanente é um conceito de aprendizagem que consiste na ideia da constante qualificação do indivíduo, seja no âmbito acadêmico, profissional ou pessoal.

Conceitua a educação permanente como uma atividade institucionalizada possuindo como principais objetivos: promoção de mudança institucional, fortalecimento das ações da equipe $e$ transformações de práticas técnicas e sociais; tendo como pressuposto para realização uma pedagogia centrada na resolutividade de problemas e sendo realizada dentro do ambiente de trabalho, promovendo com isso a apropriação do saber científico e constituindo-se em responsabilidade da instituição a qual o profissional presta seus serviços. (ALMEIDA, 1997, p. 239-249)

A retomada de alguns princípios da educação permanente, como forma de enfrentar os novos problemas que envolvem a formação dos trabalhadores gerados com introdução de tecnologias avançadas no processo de produção. Diante disso, tornase importante compreender as diferentes visões sobre esse conceito e sua importância para o processo educacional brasileiro.

A ideia de educação permanente foi sendo construída, entre as décadas de 1940 e 1970, nas plenárias realizadas pela UNESCO, com objetivo de estabelecer propostas para a educação de adultos. No relatório final, propõem-se que:

Deve-se fazer com que cada indivíduo saiba conduzir o seu destino, num mundo onde a rapidez das mudanças se conjuga com o fenômeno da globalização para modificar a relação que homens e mulheres mantêm com o espaço e tempo. (...). A educação ao longo de toda a vida tornase assim, para nós, o meio de chegar a um equilíbrio perfeito entre trabalho e aprendizagem, bem como ao exercício de uma cidadania ativa. (UNESCO, 2003).

Para alguns autores, a educação permanente proposta nessas plenárias continham, de forma implícita, a finalidade de preparar mão-de-obra e consumidores para a reprodução do capital. 
O ideal da educação permanente foi amplamente debatido no Brasil antes do golpe militar, em 1964. O educador Paulo Freire foi um dos grandes seguidores da educação permanente, mas com um viés associado à emancipação e à promoção humana do trabalhador. Sua visão da educação permanente de adultos continha propósitos político-ideológicos de conscientizar e mobilizar grupos sociais excluídos, ou seja, seu trabalho traduzia-se na concepção de educação enquanto prática libertadora do trabalhador.

No período militar, as políticas de educação permanente ficaram praticamente restritas às ações governamentais do programa de educação de adultos conhecido como Mobral. Esse programa teve poucos resultados concretos, pois os seus princípios estavam desvinculados da realidade social dos jovens e adultos que se pretendia educar.

$\mathrm{Na}$ literatura sobre a educação permanente é possível identificar vários princípios divergentes, alicerçados em pressupostos político-ideológicos dos seus autores.

Para Furter (1970) a educação permanente não pode ser reduzida nem a uma educação "extra-escolar", nem "complementar", nem "prolongada", nem tampouco "de adultos", porque todas estas interpretações só veem uma parte do problema.

Na sua concepção, a educação permanente é dialética, com um duplo processo de aprofundamento, tanto da experiência pessoal quanto da vida social global, que se traduz pela participação efetiva, ativa e responsável de cada sujeito envolvido, qualquer que seja a etapa da existência que esteja vivendo.

Ainda na visão desse autor, a educação permanente contribuiria para o aperfeiçoamento constante da formação profissional, num contexto histórico marcado pela velocidade das mudanças que ocorreram no mundo da produção em função do avanço tecnológico. A sua defesa da educação permanente está alicerçada na tese de que a alfabetização funcional associada à educação fundamental poderá integrar o que ele chama de forças ociosas e disponíveis para a construção de uma sociedade industrial. 
Mais recentemente, tem surgido textos de autores que propõem um conceito de educação permanente baseado num processo educativo contínuo privilegiando todos os espaços de ensino-aprendizagem empresa, escola, associações etc., partindo de uma situação-problema com o intuito de superá-la e transformá-la numa situação desejável.

Numa abordagem mais pragmática, há autores que defendem que a educação permanente dos profissionais deve constituir parte do pensar e fazer dos trabalhadores, visando proporcionar-Ihes o crescimento pessoal e profissional, com vistas a sua inserção no mundo do trabalho. No entanto, Gadotti (1987) chama a atenção para a falsa promessa que se cria entre os trabalhadores de que a educação permanente, ao proporcionar o aumento de formação profissional, irá garantir condições de acessibilidade e de manutenção no trabalho. Suas preocupações fundamentam-se na ideia de que o trabalhador tenha a ilusão de que a educação seja "a alavanca da transformação social".

Demo (1994) propõem que a formação do trabalhador seja permanente e baseada no lema "aprender a aprender" e "saber pensar". Ele vê aspectos positivos na educação permanente que é vista sob o prisma da qualidade total. Destaca também que a educação permanente baseada na "qualidade total" não ressaltar o compromisso com a qualificação humana, por centrar-se no conhecimento e na educação, ela poderá levar à construção e à participação na sociedade, desde que se fundamente no compromisso, sobretudo com a qualificação humana, não só no plano material, mas, principalmente, nos planos moral e no ético.

Ainda numa perspectiva pragmática da educação permanente ou da educação continuada, surgiram também as discussões em torno da necessidade de oferecer aos trabalhadores um processo educacional no qual o próprio trabalhador pudesse desenhar, de acordo com suas necessidades/interesses, as etapas de sua trajetória profissional. Nesse sentido, defendeu-se a necessidade de o Estado promover a ampliação da educação básica comum a todos e a adoção de cursos de formação profissional nas mais diferentes áreas do conhecimento, com itinerários formativos 
flexíveis, que possibilitassem aos trabalhadores retornar constantemente aos estudos acompanhando as transformações colocadas pela realidade do mundo do trabalho.

Revigorando as teses centradas na educação permanente, nas últimas décadas surgiram vários conceitos e terminologias relacionadas à ideia de educação como um processo que deve ser prolongado por toda a vida. $\mathrm{Na}$ análise dos textos sobre essa temática, constata-se que essa educação permanente é entendida, de acordo com o ponto de vista dos autores, como formação contínua, dentre outros. As propostas têm em comum a ideia de que a atualização continuada proporcionará ao trabalhador condições de adequar-se num contexto acelerado do processo de transformações do mundo do trabalho.

$\mathrm{Na}$ França, o discurso da educação permanente ressurgiu com força, nas décadas de 1980 e 1990, como uma reação imediata aos problemas colocados pela necessidade de capacitar trabalhadores para atender a demanda de trabalho das grandes indústrias. Esse discurso contém um viés ideológico, pois a proposta de educação permanente como está sendo defendida visa a atender as exigências de rentabilidade do capital.

Um dos objetivos da educação permanente é possibilitar ao trabalhador que possa construir sua trajetória profissional ao longo de sua vida.

Motta (1984), defende a ideia de que as instituições escolares e as demais instituições públicas ou privadas devem estar preparadas para oferecer educação continuada aos trabalhadores, educação que acompanhe as mudanças aceleradas das inovações tecnológicas no sistema produtivo.

Nessa perspectiva, há autores que defendem a ideia de que as instituições escolares e as demais instituições públicas ou privadas devem estar preparadas para oferecer educação continuada aos trabalhadores, educação que acompanhe as mudanças aceleradas das inovações tecnológicas no sistema produtivo. Para esses autores, torna-se necessário que os cursos possam dar uma educação integral, no início da formação do cidadão, e uma formação profissional em diferentes áreas de atuação, 
seja na escola formal ou na empresa ou em outras instituições, e aumentando os espaços educativos, de modo a que o trabalhador possa entrar ou retornar aos cursos de acordo com as suas necessidades e as do mundo do trabalho em transformação.

\section{ESCOLA, TRABALHO E GLOBALIZAÇÃO}

A revolução tecnológica das últimas décadas foi resultado da necessidade de contornar crises do sistema capitalista, que marcaram a década de 1960 e culminou com a crise do petróleo, em 1973. Essa revolução impulsionou mudanças significativas no antigo padrão fordista/taylorista de produção e de gestão. Uma das mais significativas transformações impulsionadas por esse processo foi a reestruturação do espaço geográfico da produção. A necessidade de ampliação da acumulação de capital levou as grandes empresas a buscarem regiões onde o capital encontrasse condições de se multiplicar.

Como forma de reverter o quadro de crise, os capitalistas elaboraram estratégias competitivas visando a redução dos custos de produção, do aumento da produtividade e da qualidade do produto. Tornava-se, portanto, imprescindível, para os capitalistas, encontrar regiões do mundo onde pudessem expandir o capital. Nesse sentido, era preciso que nesses locais houvesse atrativos tributários, pouca pressão sindical, trabalhadores disciplinados, com um mínimo de qualificação profissional e, sobretudo, com salários baixos.

Esse processo de deslocamento da produção para outros mercados tinha estreitas relações com o avanço tecnológico nas áreas de telecomunicações, de informatização e de transportes. A necessidade da ampliação do capital criou as bases para a mundialização dos mercados e, portanto, para o que se convencionou chamar de globalização econômica que, na verdade, não se limitou à esfera econômica, mas teve desdobramentos profundos em toda a sociedade: no mundo do trabalho, na organização política dos Estados Nacionais e nas relações sociais e culturais.

A fábrica global é tanto metáfora, quanto realidade, altamente determinada pelas exigências da reprodução ampliada do capital. No âmbito da globalização, revelam-se, às vezes, transparentes $e$ 
inexoráveis os processos de concentração e centralização do capital, articulando empresas e mercados, forças produtivas e centros decisórios, alianças, estratégias e planejamentos de corporações, tecendo províncias, nações e continentes, ilhas e arquipélagos, mares e oceano. (IANNI, 1994, p.12 e 13).

A globalização, que tem sido utilizada hoje para caracterizar o processo de intensificação das relações econômicas entre as nações do mundo, não é um fenômeno recente. A história tem nos mostrado que diferentes povos, em diferentes períodos, procuraram intensificar suas relações comerciais, sobretudo por meio da dominação política e cultural.

Santos (2002), olhando o processo de globalização, parece que estamos perante um fenômeno multifacetado com dimensões econômicas, políticas, culturais, religiosas e jurídicas interligadas de modo complexo.

A colonização europeia entre os séculos 16 e 19, por exemplo, uniu praticamente todos os continentes ao processo de acumulação primitiva do capital.

No entanto, o atual processo de globalização encontrava limites de ampliação na formação dos Estados Nacionais, que tinham barreiras alfandegárias e limitava a circulação de mercadorias e do trabalho. Nesse contexto, pode-se compreender melhor a instituição de políticas neoliberais em vários países da órbita do sistema capitalista.

Por mais paradoxal que pareça, na base desta crise está fundamentalmente a crise do capital que, para manter-se e recuperar taxas históricas de exploração, desmantela, sob o ideário neoliberal da desregulamentação e privatização, os direitos sociais conquistados pelos trabalhadores, de forma assimétrica em diferentes partes do mundo, especialmente neste último século. (FRIGOTTO, 2000, p.11)

O processo de globalização emergiu alicerçado no discurso liberal sustentado na tese de que o Estado de Bem-Estar Social e o Estado Intervencionista eram incapazes de solucionar os problemas decorrentes da crise do capitalismo. Nesse sentido, os capitalistas, liderados por grandes organizações econômicas, exerceram pressões políticas que culminaram com adoção de medidas do receituário liberal que apregoava 
a necessidade de o Estado distanciar-se do domínio econômico por meio das políticas de privatizações, enxugamento da máquina administrativa e da abertura da economia, com a eliminação ou redução de taxas sobre produtos importados.

A criação desse Estado mínimo traria problemas ainda mais graves para os trabalhadores. Se de um lado, a reestruturação da produção e do trabalho criou condições de precarização nas relações do trabalho e de desemprego, por outro, o Estado perde capacidade de continuar mantendo as políticas públicas em setores considerados fundamentais, como educação, saúde e direitos previdenciários e trabalhistas.

As máquinas modernas por si só não são capazes de aumentar a produtividade. Elas obrigam os trabalhadores a acelerar a velocidade das operações. Com as novas técnicas de organização do trabalho, muitas vezes, os intervalos de paradas são eliminados. Além da energia muscular, o trabalhador é obrigado a uma concentração maior, o que ocasiona desgaste psicológico. A tensão emocional é constante e as doenças profissionais crescem assustadoramente. São novas formas de exploração assalariada. (BERTOLINO, 1997, p.20).

A noção de globalização está, também, associada ao declínio do Estado Nacional. Aquela convicção de que alguns países tinham a hegemonia, ou seja, o domínio sobre outros, começa a ceder lugar a uma ideia de descentralização do poder; fenômeno associado à emergência dos blocos econômicos e das poderosas organizações internacionais. Quem efetivamente se organiza e detêm o poder no atual estágio do desenvolvimento do capitalismo global são as grandes empresas transnacionais que ditam e impõem as normas na economia mundial. Dessa forma, os Estados Nacionais tornaram-se vulneráveis, uma vez que seu poder de execução das políticas públicas ficou subordinado aos interesses do capital internacional.

Nesse contexto, emergem novas formas de dominação, nas quais os poderes econômico e político se redefinem não mais sob a ótica das fronteiras nacionais, mas numa crescente força de setores internacionais que deve ser produzido, o que deve ser consumido, como os indivíduos devem se comportar e pensar. 
A reestruturação produtiva da sociedade global e as políticas neoliberais representaram grande impacto sobre o mundo do trabalho. A adoção desses princípios no Brasil, na década de 1990, criou um cenário catastrófico para a classe trabalhadora. $\mathrm{O}$ grande debate que se instaurou no seio das organizações sindicais, nos partidos políticos, nos movimentos sociais e entre os intelectuais estava pautado nas consequências sociais da tragédia anunciada do "fim da era do emprego".

A questão emprego ganhou uma dimensão fundamental nos movimentos pela ampliação dos direitos sociais e pela qualidade de vida. Era consenso entre os setores progressistas de que o Estado e a escola teriam que ser acionados visando conter os graves problemas que estavam sendo anunciados progressivamente pelos Institutos que realizavam pesquisas socioeconômicas.

O novo modelo "flexível" de produção aliado às políticas neoliberais trouxeram e seu bojo o caráter altamente excludente da reestruturação do sistema capitalista. O grande questionamento dos setores sociais organizados e dos estudiosos da questão situava-se na esfera do Estado e da escola. Entretanto, como conciliar as necessidades urgentes da classe trabalhadora com a política de redução das políticas públicas sociais? É dentro desse contexto que os olhares dos atores sociais se voltam para a educação e para a escola, buscando encontrar nelas condições mínimas de emergir da crise que atingia todo o mundo do trabalho, gerando uma exclusão de grande dimensão social.

Para Luckesi (1994), a educação dentro de uma sociedade não se manifesta como um fim em si mesma, mas sim como um instrumento de manutenção ou transformação social. Assim, sendo ela necessita de pressupostos, de conceitos que fundamentem e orientem os seus caminhos. A sociedade dentro da qual ela está deve possuir alguns valores norteados de sua prática.

A escola não é um local distante da realidade social. Ela está inserida dentro do contexto de contradições que se aprofundaram com as transformações originárias das mudanças advindas da reestruturação do sistema capitalista e do modelo político imposto pelos detentores do grande capital. 
É nesse cenário de mudanças que a sociedade volta seus olhares para escola e discute o papel da educação na formação profissional articulada à educação geral. Há consenso em relação à importância do papel da escola na revalorização do cidadão trabalhador, porém as visões sobre as propostas educacionais são evidentemente antagônicas. O capital tem interesse em que a escola se adapte à realidade da produção flexível, visando formar indivíduos em condições de serem absorvidos pelas empresas. Não existe aqui a preocupação em proporcionar as condições efetivas de oferecer uma educação de qualidade, uma educação profissional e ao mesmo tempo intelectual objetivando a emancipação do cidadão e sua ação transformadora.

Gallo (2005) propõe que a educação deve levar em consideração a diferença na singularidade de cada indivíduo, ou seja, essa educação surge na contemporaneidade como rompimento do método tradicional desta forma, reforçando um olhar singular, humanizado.

No entanto, cientistas sociais e educadores, de diferentes correntes do pensamento, consideram que a escola deve estar instrumentalizada de modo a responder às demandas da nova realidade social e fazer parte frente ao grave problemas do desemprego que atinge diretamente a classe trabalhadora. Mas, para eles, o papel da escola deve ser mais amplo na formação do cidadão que detenha conhecimentos técnicos interligados com conhecimentos gerais, que possibilitem ao trabalhador usufruir não apenas da riqueza produzida pelo trabalho, mas que o mesmo possa produzir-se e transformar a realidade em que vive.

\section{EDUCAÇÃO E CIDADANIA}

No Brasil, após o período da ditadura militar, caracterizado pela prepotência do poder executivo sobre os demais, pela repressão violenta aos movimentos políticos e sociais e pela instauração da censura aos meios de comunicação, reacenderam intensamente os debates que suscitavam problemáticas em torno das relações entre educação e cidadania. As discussões sobre essa temática cresceram ainda mais no contexto do processo de elaboração da nova Carta Magna de 1988. O plenário da Assembleia Constituinte foi palco de debates intensos acerca da construção dos 
preceitos constitucionais com vistas à organização e manutenção do Estado de Direito.

Uma das reivindicações defendidas por organizações sociais progressistas consistia na ampliação das políticas públicas na área da educação, como forma de contribuir para a ampliação efetiva da cidadania. Propunham que a educação, entendida como um processo de emancipação e de socialização dos saberes, tinha estreitas ligações com a conquista da cidadania.

Para Silva (2011), é importante observar seu papel articulador na difusão da cultura dos direitos humanos no país, cada vez com maior força, tanto no âmbito das políticas públicas como das organizações da sociedade civil.

Muitas sociedades, ao longo da história, estabeleceram relações entre educação e cidadania, porém com significados diversos, condicionados às especificidades histórico-culturais de cada povo. Numa perspectiva histórica, esses conceitos devem ser entendidos como construção, produzidos no interior das relações contraditórias que se estabelecem em cada sociedade.

Para Kant (1996), o homem não pode chegar a ser homem a não ser por intermédio da educação. Ele não é mais aquilo que a educação faz dele.

$\mathrm{Na}$ cidade-Estado de Atenas, o direito à cidadania constitui-se numa obrigação para os atenienses, sendo mal vistos os que não participavam das assembleias populares. Entretanto, esse direito de cidadania estava restrito aos homens livres da cidade, da chamada polis. Estavam excluídos desse direito os escravos, que eram a maioria da população, os idosos, as mulheres, os deficientes e os estrangeiros. Segundo historiadores, mais de $90 \%$ da população de Atenas não tinham direito à cidadania.

O ideal de educação, entre os gregos, consistia na formação dos homens da classe dominante para que pudessem participar ativamente da política, que era a condição imprescindível para o exercício da cidadania. A democracia ateniense, cujos princípios influenciaram na estrutura do poder político de alguns países ocidentais, estava praticamente restrita aos grandes proprietários de terra, que eram livres das atividades 
relativas ao trabalho. O ser cidadão definia-se como aquele cuja liberdade caracterizava-se pela posse da terra e por ser livre do trabalho, já que este era interpretado como incompatível com a liberdade de pensar, produzir conhecimentos e participar diretamente das atividades de natureza política. Portanto, a cidadania no mundo ateniense era uma relação que se estabelecia entre proprietários de terra, homens livres do trabalho, que exerciam funções de comando por meio da participação política direta.

A questão da cidadania ganhou novos significados a partir das ideias iluministas difundidas na Europa no século 18. As reivindicações da burguesia europeia por igualdade de direitos e liberdade de atuar nas atividades econômicas, sem a ingerência do Estado, marcaram uma nova etapa na qual houve de fato, ainda que não abrangesse a grande maioria da população, a ampliação dos direitos civis e alguns direitos políticos.

A Revolução Francesa de 1789, influenciada pelo ideal iluminista, abriu possibilidades concretas para a garantia de direitos dos homens, ainda que esses direitos estivessem praticamente limitados aos princípios da Declaração Universal dos Direitos do Homem, havendo pouca relação entre esses princípios e a ampliação efetiva dos direitos para a grande maioria da população. O que houve na verdade foi a ampliação de direitos para a burguesia, que abriu brechas para sua consolidação no poder político.

A exploração da classe trabalhadora, no período após a primeira Revolução Industrial, despertou movimentos políticos que reivindicavam, inicialmente a ampliação de direitos políticos sociais, visando a participação política e a aprovação de leis de proteção ao trabalho. Em meados do século 19, intensificaram-se as lutas operárias e as lideranças dos movimentos dos trabalhadores abandonaram as propostas de reformas da sociedade capitalista e passaram a discutir e propor projetos visando a destruição das relações de produção capitalistas e, como alternativa, idealizaram os pressupostos de uma sociedade baseada nas relações de produção comunistas. 
Esses ideais foram significativos na construção de um novo conceito de cidadania cujos fundamentos estavam imbuídos da nova concepção da valorização do trabalho. A frase de Karl Marx conclamando os trabalhadores de todo o mundo para unirem-se propiciou todo um processo de reivindicações dos trabalhadores em defesa da ampliação de direitos civis, políticos e sociais. (MARX e ENGELS, 1970)

O século 20 foi caracterizado pela luta e pela conquista de direitos políticos e sociais. Houve avanços nesse processo de conquistas. No Brasil, como resultado da organização, da mobilização e de lutas, os trabalhadores conquistaram direitos trabalhistas, direito de voto e o direito à educação. O início dos anos 1960 representou um marco histórico nas lutas dos trabalhadores em defesa da ampliação dos direitos à educação. Sob a ditadura militar houve um aumento no ingresso de crianças e adolescentes na escola, mas os indicadores revelam também que a grande maioria não conseguia manter-se na escola por causa da estrutura escolar excludente em razão das condições de vida e de trabalho da população pobre.

A luta pela ampliação do acesso e pela qualidade da escola pública, mesmo sob total repressão, continuou em plena época da ditadura. A mobilização por esse direito à educação de qualidade para todos ganhou as ruas e, em determinados momentos, representou, a um só tempo, a luta contra a ditadura e a luta pela conquista da cidadania. O período de redemocratização foi fundamental para as discussões sobre os direitos de cidadania, dentre os quais a educação era elencada como prioridade pelos movimentos sociais, pelos sindicatos de trabalhadores e pelos partidos de esquerda e da social democracia.

As transformações no mundo do trabalho criaram uma dura realidade para milhões de brasileiros que perderam os seus empregos ou foram alijados da economia formal e passaram a sobreviver à margem do processo produtivo, trabalhando em condições precárias e com baixíssima capacidade de galgar um novo posto de trabalho. 


\section{CONSIDERAÇÕES FINAIS}

Para enfrentar os desafios provenientes do avanço tecnológico, torna-se imprescindível pensar nas alternativas concretas viáveis que representem o avanço da conquista da cidadania, tendo como horizonte que a educação e o trabalho se constituem em fatores decisivos na efetivação desse ideal.

A educação, o trabalho e a cidadania devem estar inseridos no embate das lutas sociais e política na construção de uma sociedade baseada na efetiva democratização de conhecimentos e das riquezas. Vislumbram-se as possibilidades de que a escola e os educadores tenham um papel importante no processo de construção de uma sociedade inclusiva, que resgate a dignidade da mulher e do homem enquanto seres sociais e trabalhadores, uma sociedade que não exclua seu povo de sangue tupiguarani, que não exclua seu povo afrodescendente, que não exclua seu povo euro descendente, que não exclua seu povo constituído de mulheres, idosos, homossexuais e portadores de necessidades especiais, que não exclua seu povo por razão políticas e religiosas, que não exclua as minorias que, na verdade, fazem parte da maioria. Justamente a maioria que tem sofrido, mais do que nunca, os efeitos perversos da exclusão social no atual mundo do trabalho.

\section{REFERÊNCIAS}

ALMEIDA, A. R. S. A emoção e o professor: um estudo à luz da teoria de Henri Wallon. Psicologia: Teoria e Pesquisa, v. 13, $n \cong 2$, p. 239-249, 1997.

BERTOLINO FILHO, J. Motivação. Campinas, SP: Alínea, 1997, p.20.

DEMO, Pedro. Pesquisa e construção do conhecimento: metodologia científica no caminho de Habermas. Rio de Janeiro: Tempo Brasileiro, 1994.

DEMO, Pedro. Avaliação quantitativa. São Paulo: ed. Cortez, 2003.

FREIRE, Paulo. Educação como Prática da Liberdade. Rio de Janeiro, Paz e Terra, 30ํe edição, 2007. 
FRIGOTTO, G. (org). Educação e crise do trabalho: perspectivas de final de século. 7 ed. Petrópolis, RJ: Vozes, 2000, p. 11.

FURTER, Pierre. Educação e vida. Petrópolis - Rio de Janeiro: Vozes, 1970.

GALLO, S. Sob o signo da diferença em torno da educação para a singularidade. In: SILVEIRA, Rosa Maria Hessel (org). Cultura. Poder e Educação. Um debate sobre estudos culturais em Educação. Canoas, ULBRA, 2005.

GADOTTI, Moacir, 1987. Educar para um outro mundo possível. São Paulo, Publisher Brasil.

GADOTTI, M; ROMÃOJ. E. (orgs). Educação de Jovens e Adultos: teoria, prática e proposta. 7. Ed. São Paulo: Cortez: Instituto Paulo Freire, 2005.

IANNI, Octavio. (1994, p.12 e 13). Teorias da globalização. 4ª ed., Rio de Janeiro, Civilização Brasileira.

KANT, Immanuel. A paz perpétua e outros opúsculos. Lisboa: Edições 70, 1996, p. 73.

LUCKESI, Cipriano Carlos. Filosofia da Educação.7ª ed. São Paulo:Cortez,1994, p.30.

McLUHAN, M. Os meios de Comunicação como extensões do homem. São Paulo: Cultrix, 1969.

MARX, Karl; ENGELS, Friedrich. Lutas de Classes na Rússia. (Tradução: Nélio Schneider) São Paulo: Boitempo, 1970. p.208.

MARX, Karl. O Capital. São Paulo: Abril Cultural, 1983.

MOTTA, F. C. P. Administração e participação: reflexões para a educação. Revista da Faculdade de Educação da USP, v. 10, n. 2, p. 199-206, jul./dez. 1984. 
ORSO, Paulino. As Possibilidades e Limites da Educação na Sociedade de Classes. IX Seminário Nacional de Estudos e Pesquisa História, Sociedade e Educação no Brasil. Universidade Federal da Paraíba. João Pessoa Anais Eletrônicos ISBN 978-85-7745-551-5.2012.

SANTOS, Antonio Raimundo. Metodologia científica: a construção do conhecimento. Rio de Janeiro: DP\&A, 2002.

SILVA, Aida M. M. Direitos humanos na docência universitária. In: PIMENTA, Selma Garrido; ALMEIDA, Maria Isabel (Org.). Pedagogia universitária: caminhos para a formação de professores. São Paulo: Cortez, 2011.

UNESCO, Padrões de Competências em TIC para Professores: Diretrizes de Implementação. 2003.

Enviado: Setembro, 2020.

Aprovado: Outubro, 2020. 